\title{
Specific Features of Child Psychiatry in a Multidisciplinary Hospital, Morocco
}

\author{
Abdeslam Benali*, Fadoua Oueriagli, Wydad Hikmat, Amine Laffinti, Imane Adali, Fatiha Manoudi1 and Fatima Asri
}

Research Team For Mental Health, University Cadi Ayyad, Marrakesh, Morocco

\begin{abstract}
Modern child psychiatry responds to increasing demands of confused parents and sometimes of perplex teachers. The objective of this kind of work is to illustrate the particularities of child psychiatry in a multidisciplinary hospital, defining the major fields of application of child psychiatry liaison and the difficulties related to this activity. This article illustrates the importance of identification and prevention of the suffering children, privileging a close collaboration between different actors, respecting the role of each other.
\end{abstract}

Keywords: Child psychiatry; Multidisciplinary hospital; Network

\section{Introduction}

The concept of child psychiatry is nowadays well integrated by health professionals. In fact, there has been a significant increase in demand for medical care [1]. Therefore a reflection articulating the psyche and the soma is required in order to afford a global approach and treatment [2]. The main objective of our work is to illustrate the particularities of child psychiatry in a multidisciplinary hospital, defining the major fields of application and difficulties related to this activity. We discuss this work in three clinical cases that seem to reflect the vast majority of patients that we receive as part of the liaison psychiatry, child psychiatrist is an integral part of pediatric teams. Noted in this work that patient consent was obtained. All parents gave their consent to include the clinical history with their children.

\section{The historical aspects}

Liaison psychiatry has been developed respectively in USA and in European countries between 1930s and 1970s. The first child hospitals played initially a social role. Their main aim was to fight off poverty, and then they gradually became therapeutic institutions. At first, it did not seem particularly useful to have a child psychiatry team in pediatric services. It is through the intermediary of psychoanalysis that the interest of the psyche made his entrance in the pediatric hospitals; child and adolescent psychiatry will adopt later other common theories to child development, and specific therapeutic approaches from adult psychiatry. This will gradually lead to the development of a bio-psychosocial model taking into account: neurobiological, social, environmental and psychological factors.

\section{Clinical Illustrations}

\section{Suicide attempt case}

A 17-year senior high school teenager was sent by his physician for a psychiatric evaluation, because he was lost of all interest and pleasure This teenager tried to commit suicide 8 days before by taking hypnotic pills. During the interview, he was tense, with frozen facial expression, he had a great difficulty expressing himself, seemed lost in his thoughts and the dialogue was hard at first.

We understood later that our patient just moved from Casablanca and integrated a new high school in the city of Dakhla in the south of Morocco; he also said that he was hopeless, disappointed because he got a bad grade for the very first time of his life. He added that he had many suicidal scenarios in mind before talking those pills. This suicide attempt is a real desire for death and intentionality is strong. The suicidal act was planned and premeditated. We have not found personal psychiatric history. However, his mother was treated for depression for several years.

Meanwhile, his father who accompanied him to the hospital assured us that his son has always been "quiet, studious and serious..." $\mathrm{He}$ believed that this was probably just an accident. Biographical elements are very rich: the parents are simple people, both retired. They have no sense for entertainment. Their affection toward their children was very limited if not absent. The main conversation ever engaged was about the assets. He always felt furious but has never expressed it openly. $\mathrm{He}$ feared to hurt his parents' feelings.

Our patient was kind of a loner, never had a girlfriend and was not able to make simple choices such as choosing his own hair cut. The suicide attempt of this brilliant schoolboy was the final spot of a long neurotic distortion in his development. The rather ordinary triggering motive: the bad grade was only the straw that broke the camel's back. The invisible and the most important part of the iceberg is represented by: his low self esteem, his history of depression with a weakened ego, hidden anger, as well as the conflictual relationship with his demanding parents.

He felt trapped into their "old fashioned" lifestyle, which prevented him from having a fulfilled life, the only way to overcome this was his rebellious behavior (reckless driving, speeding ...) considered by our team as suicidal equivalents.

The aggressiveness of the teenager is diverted from its normal outlets. Instead of using it to develop his own personality, to enhance his autonomy, he turned it against himself. The unbearable isolation from the contemporary group, as well as the emotional distancing from his parents drowned him in an awful feeling of loneliness. Emotional relationship with parents offers him no support; there is no more access to peers of his age. The only escape he had was his imagination, he was always picturing running away and using drugs, while in reality he remained bound by his guilt. The tension increases and the situation become increasingly hopeless.

*Corresponding author: Abdeslam Benali, Research Team For Mental Health University Cadi Ayyad, Marrakesh, Morocco, Tel: 00212 661402302; E-mail: abdes.benali@yahoo.fr

Received March 28, 2014; Accepted November 07, 2014; Published November 14,2014

Citation: Benali A, Oueriagli F, Hikmat W, Laffinti A, Adali I, et al. (2014) Specific Features of Child Psychiatry in a Multidisciplinary Hospital, Morocco. J Psycho Abnorm Child 3: 132. doi:10.4172/2329-9525.1000132

Copyright: ( $\odot 2014$ Benali A, et al. This is an open-access article distributed under the terms of the Creative Commons Attribution License, which permits unrestricted use, distribution, and reproduction in any medium, provided the original author and source are credited. 
Nothing in the behavior of the patient indicates the imminent suicidal act. His decision to end his life was not perceived neither by his classmates nor his parents, furthermore the Suicidal equivalents were falsely interpreted as "madness". The parents didn't realize that their kid was living a crisis; they didn't notice the change in his mood, meanwhile he was obsessed with death. Their teachers, classmates were devastated and saddened by his suicide attempt.

After being diagnosed, our patient received a prescription of an antidepressant (50 mg of Sertraline per day for a period of 12 months), as well as a regular psychotherapeutic work (1 session per week). The results were very good, and the patient resumed his studies and was very comfortable to come to every planned session.

Both parents have received psychological help, in the form of couples therapy.

\section{Childhood depression case}

A 10 -year-old boy was sent by his pediatrician to the $4^{\text {th }}$ Military Hospital for a psychiatric consultation. In his medical record, the physician related that he always had digestive problems. Many tests were run and were all negative.

The patient is the oldest of his siblings, he was a desired child, and his parents got divorced after the birth of his little sister, 5 years ago. $\mathrm{He}$ had a normal psychomotor development, and an ordinary schooling path. Until the day his mother started receiving phone calls from school complaining about his excessive absenteeism. It was hard for him to wake up, and once at school he had nausea and vomiting which forced him to return back home immediately, he also suffered from permanent headache and abdominal pain. The symptoms became increasingly frequent and disabling and he became aggressive and constantly threatening to commit suicide.

We were confronted to a child with diverse and varied symptoms, school decline, access of anger and self mutilation. We gave him occasionally levomepromazine to manage his insomnia (15-20 mg per day) administered orally at bedtime.

The psychotherapeutic work aimed essentially to point and addresses the family dynamics. The parents were isolated from the world, the mother was often depressed and the father was a violent alcoholic. The child gradually integrated the link between his physical disorders and the conflict within the parental couple. The follow-up has created a space for dialogue for the young patient, and therefore an access to mental health care.

It allowed us also to treat the depressed mother. Psychological support for the couple has been advocated. These results were significant. The evolution after 8 months was relatively good, nevertheless we observed the emergence of an OCD justifying the introduction of an antidepressant (fluoxetine $20 \mathrm{mg}$ per day), which was effective and well tolerated, with as subsequent project, C.B.T sessions.

\section{School failure case}

This is a young 15-year-old girl sent to us directly by her teacher who noticed various behavioral problems for a psychiatric consultation. Her medical records showed that her psychomotor development was perfect. However she was diagnosed with celiac disease and had an accident recently with multiples and severe head trauma.

The mother claims that her daughter's behavior has changed ever since the accident. But for her it was "normal" with the adolescence crisis, which is intensified by the father's absence.
She became aggressive even toward her teacher, turbulent and sometimes insomniac. She also finds it difficult to be attentive during the class. This causes her enormous difficulties in learning, reading and writing. These difficulties appear to be related to personality changes and major neurocognitive disorders. These problems appeared a few weeks after the highway accident, followed by a secondary enuresis and severe headaches. She seems sensitive to the therapeutic relationship; her gestures and mimicry reflect sadness and apathy. She points out to her problem to integrate the group at school, fearing at the same time to loose her future.

Due to the lack of means and specialized personnel to introduce this patient in the hospital for a certain time, we opted to grant her short and frequent psychiatric sessions. The psychomotor test reveals big problems, both at the level of corporal scheme and temporal-spatial organization. Neurocognitive evaluation shows the attention disorders. The attention is selective and fluctuating without instability or impulsivity. Memory is somehow more visual than aural. The memory of work is very disturbed.

There are also language problems concerning her way of expressions. The field of gnosis, praxis and graph-motor is preserved. We were able to start a treatment (Carbamazepine: $400 \mathrm{mg}$ per day) and psychotherapy. Working with a psychomotor and speech therapist at a rate of twice a week Helped in the management of neurocognitive disorders. The evolution was marked by a significant decrease in behavior problems. But she remained in great resentment against the school board. Family brought up the idea of moving to Casablanca, to enable the girl to continue her education in another institution.

\section{Discussion}

This work allowed us to seize some particularities of the child psychiatric practice within a multidisciplinary hospital. It seems to us that we can indeed, through clinical samples, illustrate the different aspects of child psychiatry, and identify some pitfalls and difficulties related to this activity. The first patient illustrates a case of "emergency", which corresponds to the unscheduled intervention demands. A concept that refers to three types of situations to which a psychiatrist is required to intervene without delay:

1 - The "immediate emergency", emergencies that involve a quick intervention. Those include teenagers and children over 13 years old [3-5]. Those are especially suicide attempts, acute psychosis, anorexia, bulimia, post-traumatic-stress-disorder, neuropsychiatric disorders related to organic diseases (epilepsy, metabolic disorders...).

2 - "Interventions without delay", often require intervention during the day. Those correspond to our practice to seek medical advice sometime before the patient can be discharged from the hospital.

3 - "New emergencies", a situation as described by the authors that corresponds to demanding assistance from other practitioners in diagnostic evaluation, therapeutic or preventive adjustment.

We often run into difficulties within the child psychiatry practice scope. Particularly when the management of the emergency situation is inappropriate. This problem makes doctors enter ether in misunderstanding or conflict. Therefore, the ideal is to receive the request from these practitioners and provide answers as soon as possible [6,7]. We note also that the anxiety and the overwhelming emotions of parents in the context of the emergency affect considerably the child psychiatric diagnosis [8]. The anxiety disorders are considered as the most frequent. The communication with the physician becomes sometimes difficult for the psychiatrist. He must deal with a series of 
profiles facing a practitioner who confesses his incapability and gives up in front of the psychological suffering of the patient $[9,10]$. For this reason, the main task of child psychiatry remains in establishing links between many partners to make good use of the available resources by developing a real functioning network.

The second case reflects the immense majority of our clients. These are patients with functional symptoms. However, the problem keeps persisting despite all the medical investigations, which prove that the patient is free from any organic disease. Even if there is a possible genuine physical disorder, the latter can neither account for the nature, severity of the disorder, nor the distress concerning the subject. These problems are classified as somatoform disorders in accordance with the ICD 10. In literature review, recurrent abdominal pain affects between 8 to $25 \%$ of children in the general population and at the same time it represents 2 to $4 \%$ of pediatric consultations. Concerning the psychiatric level, $70 \%$ of patients come from triggering factors (parental divorce, recent mourning) so these disorders can have an impact on school assessment $[11,12]$.

The third case shows that school failure is a common reason to ask for a child psychiatric assessment. Under multiple factors, social, educational, the parents as well as the school staff when ever they see a child with schooling problems they prefer to seek a psychiatric advice. The request for such assistance must be within the framework of a rigorous medico-psychological approach for a better orientation [13]. This step must take systematically into consideration neurobiological, psychological and educational factors. These three clinical cases schematically represent the majority of our patients consulting for child psychiatry at a multidisciplinary hospital:

\section{1 - Psychiatric emergencies}

\section{2 - Somatoform disorders}

\section{3 - School failure}

4 - Other: detection of severe development disorders, sexual abuse, psychiatric disorders secondary to organic pathologies.

The size and composition of a child psychiatry team is variable. Concerning our case, it is a reduced team, by the nature force: it contains a psychiatrist and a polyvalent nurse. Our intervention as a team is done in three stages:

\section{1 - The consultation request analysis:}

The wording of the request of the consultation influences the quality of collaboration between practitioners. It must answer two questions: who is seeking the intervention and in which context? According to the doctors, the nature of demand is variable. We find that it is scalable and dynamic. This essentially depends on the different visions of the disease, childhood and child psychiatry $[14,15]$. It is essential for the practitioner to prepare and inform the patient and family about the child psychiatric consultation, to avoid paradoxical reactions.

\section{2 - The child psychiatry consultation:}

The child psychiatry consultation usually takes around 60 minutes. In most of the cases, we discover that the reason for the consultation is not the main problem for which he needs a medical intention. The interview with parents is inevitable; particularly with mothers, because most of the fathers are soldiers who serve far away from home.

\section{3 - Answers:}

After each consultation, the psychiatrist must submit the findings and proposals to the applicant, the child and parents. This response must include a clear and precise idea about the psychiatric evaluation, using a simple and accessible speech as well as therapeutic alternatives.

A child will not talk to the psychiatrist unless he is sure that his secret is safely kept $[16,17]$. The relationship between different doctors, according to Winnicott, doesn't concern only their specialties, but also the difference in their emotional attitude. The difference related to the symptom may cause disagreements; in which the recognition from the part of all the doctors can serve as a reflection of intra-psychic movement of the jointly taken care patient. This will permit elaborate constructive relationships with families $[8,18,19]$, and to get to all aspects of the disease.

Some challenges are specific to child psychiatry, inherent frustrations to this activity are divers and varied and should be discovered:

- A dissatisfaction that may arise from interventions for patients who have rarely applied for psychic assistance.

- A great part of activity, which is not directly therapeutic.

- The question of identity and the place of the child psychiatrist.

- The diagnostic uncertainty is a major dimension of medicine as medical ethics.

Finally, in equivalence between the increasing demands and the means available at the child psychiatry.

\section{Conclusion}

Modern child psychiatry responds to increasing demands of confused parents and sometimes of perplex teachers.

Consultation liaison psychiatry is an important way to reach out to children and adolescents with psychological problems and their families. There may also be stigma associated with mental illness and psychological help from a multi-disciplinary team may help assuage the parents fears as well.

This article illustrates the importance of the identification and the prevention of the suffering of children, privileging the close collaboration between different care givers, respecting the role of each other.

Finally, the intervention of the child psychiatrist, according to Graber "specialist of human, speech and the relationship" must not give up the habit other practitioners to withdraw from the most difficult questions (child abuse, disclosure of serious diseases to patients, handicap support, and chronic illness or death).

\section{Contributions of Authors}

We confirm that all the authors of the manuscript have read and agreed to its content, that readily reproducible materials described in the manuscript will be freely available to any scientist wishing to use them for non-commercial purposes. Persons listed as authors should have contributed to the manuscript per the URM criteria for authorship and contributorship.

\section{References}

1. Wiss M, Lenoir P, Malvy J, Wissocq M, Bodier C (2004) Child consultationliaison psychiatry within the hospital: a prospective study. Arch Pediatr 11: 4-12

2. Duverger P, Champion G, Malka J (2000) The child psychiatric emergencies in the pediatric emergency. French Journal of Psychiatry and Medical Psychology 40: 19-22.

3. Tomb DA (1991) Child Psychiatric Emergencies. In: Lewis M (Eds.) Child and Adolescent Psychiatry. Williams and Wilkins, Baltimore. 
Citation: Benali A, Oueriagli F, Hikmat W, Laffinti A, Adali I, et al. (2014) Specific Features of Child Psychiatry in a Multidisciplinary Hospital, Morocco. J Psychol Abnorm Child 3: 132. doi:10.4172/2329-9525.1000132

4. Maurette JL, Lejeune C, Devoitille JM (2001) Study the advice of liaison psychiatry: what motivates somatician in a general hospital to call for such collaboration? Acta Psychiatr Belg 10:100-115.

5. Rouby P, Wissocq M, Hameury L, Perrot A, Malvy J (2001) The child psychiatric emergency room at Children's Hospital. Annals of Psychiatry 16: 110-116.

6. Vidailhet C (1995) Child psychiatry emergency of a children hospital. Arch Pediatr 2: 1131-1134.

7. Desombre H, Malvy J, Wiss M (2004) Liaison child psychiatry: Organization and missions. Psychiatric report to Congress of Psychiatry and Neurology in French. Paris: Masson.

8. Clemente C, Mc Grath R, Stevenson C, Barnes J (2006) Evaluation of a waiting list initiative in a child and adolescent mental health service. Child Adolesc Ment Health 11: 98-103.

9. Woodgate M, Garralda ME (2006) Pediatric liaison work by child and adolescent mental health services. Child Adolesc Ment Health 11:19-24.

10. Sibertin-Blanc D, Rothenburger S, Kabuth (2005) Liaison psychiatry: transdisciplinary practice, an ethic of meeting. Perspectives Psy 44: 96-101.

11. Rufo M (1986) About the consulting practice of psychiatry in pediatrics. Child Neuropsychiatry $34: 522-525$.

12. Roques F, Herve MJ, Maury M (1999) Staging anxiety in a paediatric hospital: how can the play be performed ? Neuropsychiatry of Childhood and Adolescence 47: 125-133.

13. Garralda ME (2004) The interface between physical and mental health problems and medical help seeking in children and adolescents: a research perspective. Child Adolesc Ment Health 9: 146-155.

14. Duverger P, Lebreuilly-Paillard A, Legras M, Chocard AS, Malka J (2009) The consultation-liaison child psychiatrist, a practitioner of the unexpected. Neuropsychiatry of Childhood and Adolescence 57: 505-509.

15. Lenoir P, Maloy J, Desombre H, Abert B, Ould Taleb M, et al. (2009) Consultation-liaison psychiatry in pediatrics: Resources and constraints of an interdisciplinary collaboration. Neuropsychiatry of Childhood and Adolescence 57: 75-84.

16. Slowik M, Noronha S (2004) Need for child mental health consultation and pediatrician's perception of these services: a survey in the West Midlands. Child Adolesc Ment Health 3: 121-124.

17. Sayal K (2006) Annotation: Pathways to care for children with mental health problems. J Child Psychol Psychiatry 47: 649-659.

18. Woodhouse AE (2006) Reducing waiting times: using an opt-in system and changing prioritisation criteria. Child Adolesc Ment Health 11: 94-97.

19. Gerardin P (2009) Links and liaison in child psychiatry. Prevention and patient care in related pathology. Neuropsychiatry of Childhood and Adolescence 57: 452-455. 